\title{
Management of Patients with Symptomatic Gallstones: A Quantitative Analysis
}

\author{
DAVID F. RansohofF, M.D. New Haven, Connecticut WILLIAM A. GRACIE, M.D. Ann Arbor, Michigan
}

Should persons with symptomatic gallstones (i.e., those that have caused biliary pain) be treated immediately? Or may they be managed expectantly until pain recurs or a biliary complication (i.e., acute cholecystitis or pancreatitis) occurs? To assess the mortality risk of different strategies, we performed a quantitative analysis. For the expectant management strategy that requires surgery only if a biliary complication occurs, the cumulative lifetime probability of gallstone disease death in a 30-year-old man is about $2 \%$, and most deaths occur after age 65. In comparison, elective cholecystectomy has only a $0.1 \%$ rate of gallstone disease death, but all deaths occur at age 30 . The average amount of life expectancy gained by immediate cholecystectomy compared with expectant management is 52 days, which is reduced to 23 days using $5 \%$ discounting. This gain could be increased only slightly by a $100 \%$ effective and riskfree therapy such as perfected lithotripsy or medical dissolution. Results are similar for women. The results suggest that, for persons with symptomatic gallstones, the life expectancy gain of immediate cholecystectomy is relatively small and that the potential incremental gain of nonsurgical therapy is also small. For patients and physicians who believe that life expectancy is of primary consideration, the decision about therapy may be made primarily on non-mortality considerations. Some patients and physicians may decide that the risk of symptomatic gallstones is low enough that a policy of expectant management may be acceptable.

From the Departments of Medicine, Yale University, New Haven, Connecticut, and The University of Michigan School of Medicine, Ann Arbor. Michigan Or. Ransohoff is a Henry I Kaiser Family Foundation Faculty Scholar in Genera Internal Medicine. This work was supported in part by a grant addressed to David F. Ransohoff, M.D., Department of Medicine, Yale University School of Medicine, IE-61 SHM, P.O. Box 3333, New Haven, Connecticut 06510-8025. Manuscript submitted February 13, 1989, and accepted in revised form July 12,1989 . ome authorities recommend cholecystectomy after $S_{\text {an }}$ episode of biliary pain in persons with gallstones [1-3]; others suggest that temporizing may be acceptable to see whether biliary pain recurs or whether a biliary complication such as acute cholecystitis occurs $[4,5]$. Recent natural history data indicate that, after an episode of biliary pain, the probability of having at least one more episode of pain over the next two years is about $70 \%[6]$; the probability of biliary complications, however, is substantially lower [6]. Thus, if a patient's primary goal is to avoid further pain episodes, prompt intervention may be chosen. On the other hand, some patients do not want cholecystectomy and may not want (or not be a candidate for) nonsurgical therapy [7-9]. For such a patient, is the likelihood of biliary complications high enough to make expectant management unacceptable? The answer depends in large part on the magnitude of the probability of developing a biliary complication and on the probability of death once a complication has occurred. The purpose of this article is to assess quantitatively the risks of expectant management and the rationale, advantages, and disadvantages of therapeutic alternatives for persons with symptomatic gallstones.

\section{METHODS}

\section{Management Alternatives}

Three principal management strategies are assessed. One is immediate cholecystectomy after the episode of pain; two different types of expectant management are considered. Nonsurgical therapies are considered in the Comments section.

STRATEGY A-IMMEDIATE CHOLECYSTECTOMY: Strategy A is to perform a cholecystectomy after the episode of biliary pain. This is a commonly recommended strategy [1-3].

STRATEGY B-EXPECTANT MANAGEMENT UNTIL PAIN RECURS OR UN'IL A COMPLICA'TION OCCURS: The second strategy is to delay cholecystectomy either until pain recurs or until a biliary complication occurs; in either event, a cholecystectomy is done.

STRATEGY C-EXPECTANT MANAGEMENT UNTIL A COMPLICATION OCCURS: The third strategy is to delay cholecystectomy until a biliary complication occurs; at the time of the complication, a cholecystectomy is done. The difference between this strategy and the previous one is that, in this strategy, recurrent pain may be tolerated by the patient. This strategy has been considered to be possibly acceptable by some authorities $[4,5]$. Furthermore, we believe that this strategy has in fact been chosen by many patients with symptomatic gallstone disease [10].

\section{The Decision Tree}

The structure of the decision tree for this problem is similar to the one we previously described for asymp- 
tomatic gallstones [11]. Thus, the same consequences can occur for persons with symptomatic gallstones as for persons with asymptomatic gallstones; the occurrence rates of the consequences are different. Also we have included in this analysis the occurrence of fatal gallbladder cancer.

\section{Probability Values}

Rates of occurrence are required for the following clinical events: (1) natural history of symptomatic gallstones (i.e., the yearly rate to develop biliary pain or a biliary complication); (2) the operative mortality rate for elective cholecystectomy at each age; (3) the operative mortality rate at each age for a biliary complication such as acute cholecystitis or common duct stone; (4) the rate to develop gallbladder cancer at each age.

(1) NATURAL HISTORY OF PERSONS WITH SYMPTOMATIC GALLSTONES: The long-term natural history of symptomatic gallstones is not well known. The shortterm natural history of symptomatic gallstones is well described for the placebo group of the National Cooperative Gallstone Study (NCGS) [6]. We consider the subgroup of persons in the NCGS who had had recent symptoms (i.e., within one year of entry into the study) to be generally representative of persons with biliary pain, and we have used those data in this analysis. Two studies [12,13] about natural history are less pertinent because the subjects were hospitalized. Other studies provide few data about symptom status at entry [14] or about follow-up results $[10,15]$. Only the NCGS [6] provides an actuarial analysis of follow-up.

Using the data from the NCGS, we calculated the short-term natural history of persons with symptomatic gallstones in the following way. Of the 112 persons who had had recent symptoms, $69 \%$ developed pain (i.e., biliary colic or prolonged pain) over the next two years, and $6 \%$ required cholecystectomy. We assumed that the rate to develop pain did not change during each of those two years. Using life-table techniques, we calculated the rate for pain to be $41 \%$ per year and for a biliary complication to be $3 \%$ per year.

For the long-term perspective of this analysis, we make an important assumption that the yearly rates to develop pain or a complication remain constant over a patient's lifetime. Uncertainty about this assumption is considered in the Comments section.

(2) OPERATIVE MORTALITY RATES FOR CHOLECYSTECTOMY: The age-specific operative mortality rates for elective cholecystectomy and for acute biliary complications have been previously described [11]. For example, the operative mortality rate for elective cholecystectomy in a 30 -year-old man is $0.107 \%$ and for a 60 -year-old man is $1.215 \%$. For cholecystectomy after a biliary complication, the rates are $0.427 \%$ and $4.86 \%$, respectively [11].

(3) LIFE EXPECTANY: Life expectancy values were taken from published sources [11].

(4) GAILBLADDFR CANCFR: The yearly rate to develop gallbladder cancer in persons with gallstones is not well known. A recent cohort study [16] reported a rate of nine cases per 10,000 person-years of follow-up. This rate may be an overestimate because two of the five persons who developed cancer of the gallbladder may have already had cancer at the time they were entered into the study. We are unaware of other cohort data about gallbladder cancer incidence.

\begin{tabular}{|c|c|c|}
\hline \multicolumn{3}{|c|}{$\begin{array}{l}\text { Input Data: Rates of Gallbladder Cancer Estimated for Use in } \\
\text { Analysis* }\end{array}$} \\
\hline Age (years) & (cases per 100,000 per year) & White Woman \\
\hline $\begin{array}{c}30-39 \\
40-49 \\
50-59 \\
60-69 \\
70-79 \\
\geq 80\end{array}$ & $\begin{array}{r}0.7 \\
1.3 \\
3.8 \\
9.9 \\
19.7 \\
30.1\end{array}$ & $\begin{array}{r}0.3 \\
1.9 \\
4.2 \\
10.7 \\
22.6 \\
33.7\end{array}$ \\
\hline
\end{tabular}

${ }^{*}$ See text for details.

Using non-cohort data, we have estimated the yearly incidence of gallbladder cancer in the following way. The yearly numbers of deaths from gallbladder cancer for 10-year age groups in the United States were obtained for the years 1983 through 1985 from the NCGS [17]. The total numbers of persons with gallstone disease in each age group were calculated using an estimate of age-specific prevalence of gallstones [18] and the population of the United States in 1980 [19]. Using the first number as the numerator and the second as the denominator and then dividing the numerator by the denominator, the age-specific yearly incidence rates of gallbladder cancer were calculated (Table I). This method of estimation has limitations. The use of an age-specific cancer incidence presumes that age is of primary importance in determining risk. In fact, the duration of gallstone disease may be more important, but data about duration are unavailable. Further, this estimate does not consider the possibility that cancer risks of symptomatic and silent gallstone disease may differ. Whether the uncertainty about cancer rates is likely to be important is assessed in sensitivity analysis.

\section{Calculations}

Calculations were performed on an IBM/PC computer using a Lotus 1-2-3 (release 2.01) spreadsheet approximately $70 \mathrm{~KB}$ in size. This method, which models a Markov process, provides results identical to those previously reported using a mainframe computer and the language APL [11].

The three management strategies were compared by counting the numbers of deaths that would occur each year for hypothetic cohorts of 100,000 persons followed to age 100 from ages 30 years, 50 years, and 70 years. Life expectancy losses were calculated by multiplying the numbers of deaths occurring in each year times the life expectancy for a person at that age. Life expectancy losses were calculated using no discounting and also using a conventional 5\% discount rate. Discounting is used to reflect that a year of life lost immediately is valued more highly than the same year of life lost in the future. The base case analysis utilizes our best estimates for natural history and operative mortality. Sensitivity analysis is used to assess the importance of uncertainty about these estimates.

\section{Additional Assumptions}

1. A person considered in this analysis has already had biliary pain (i.e., colic) but not a biliary complication. 


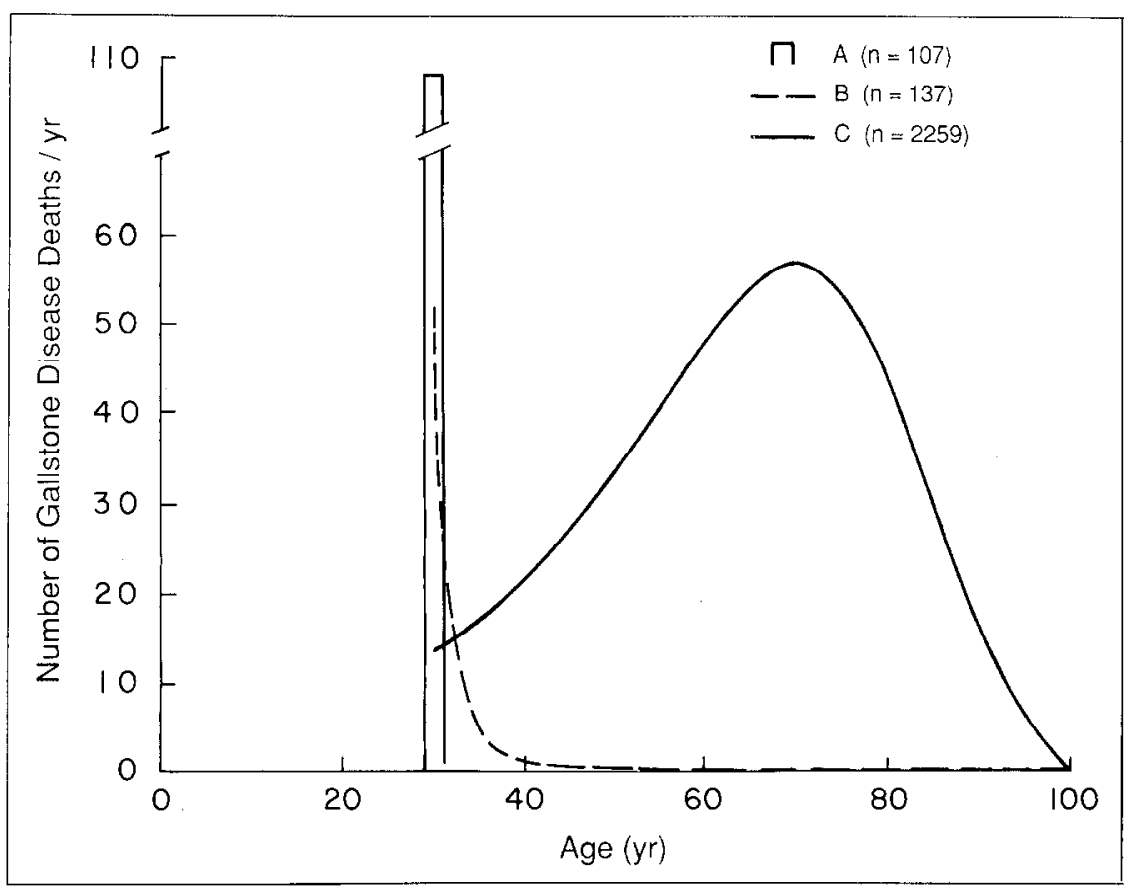

Figure 1. Results of base case analysis for 100,000 30-year-old men: gallstone disease deaths for three strategies. In parentheses are the cumulative numbers of deaths for each strategy to age 100 . In this analysis for natural history in Strategy $B$, the rate of pain is 0.41 /year and the rate of biliary complications is 0.03 /year; for Strategy $C$, the rate of biliary complications is 0.03 /year.

\section{TABLE II}

Risk of Gallstone Disease Death for a 30-Year-Old Man with Symptomatic Gallstones

\begin{tabular}{|c|c|c|c|c|c|c|c|}
\hline \multirow[b]{3}{*}{ Strategy } & & \multicolumn{6}{|c|}{ Cumulative Risk of Gallstone Disease Death (\%) } \\
\hline & & \multicolumn{2}{|c|}{ Non-Cancer } & \multicolumn{2}{|c|}{ Cancer } & \multicolumn{2}{|c|}{ Total } \\
\hline & & By Age 50 & By Age 100 & By Age 50 & By Age 100 & By Age 50 & By Age 100 \\
\hline \multicolumn{8}{|l|}{ Immediate intervention } \\
\hline A-Cholecystectomy & & 0.11 & 0.11 & 0 & 0 & 0.11 & 0.11 \\
\hline \multirow{2}{*}{\multicolumn{2}{|c|}{$\begin{array}{l}\text { Expectant management } \\
\text { B-Until pain or a complication* } \\
\text { C-Until a complication }\end{array}$}} & & & & & & \\
\hline & & 0.14 & 0.14 & 0 & 0 & 0.14 & 0.14 \\
\hline \multirow{5}{*}{ Rate of complication } & $0.0075 /$ year & 0.15 & 1.26 & 0.02 & 0.19 & 0.17 & 1.45 \\
\hline & $0.015 /$ year & 0.27 & 1.88 & 0.02 & 0.15 & 0.29 & 2.03 \\
\hline & 0.03 /yeart & 0.45 & 2.17 & 0.01 & 0.09 & 0.46 & 2.26 \\
\hline & $0.06 /$ year & 0.63 & 1.67 & 0.01 & 0.03 & 0.64 & 1.70 \\
\hline & (0.10/year & 0.69 & 1.08 & 0.01 & 0.01 & 0.70 & 1.09 \\
\hline
\end{tabular}

* Rate of biliary pain: 0.41 /year; rate of biliary complication: $0.03 /$ year.

$\dagger 0.03$ /year is "base case" rate for Strategy C.

2. The principal biliary complications of gallstone disease are acute cholecystitis and common duct stone. We do not explicitly consider acute pancreatitis because pancreatitis occurs less frequently [15] and causes fewer gallstone-related deaths [20,21].

3 . The mortality from acute cholecystitis is entirely due to operative mortality. We believe that this assumption is justified because current policy suggests early operation when a biliary complication occurs $[22,23]$. We do not consider explicity the possibility of a biliary complication that receives no operation.

4. In a person who survives cholecystectomy, life expectancy is not decreased compared with that of the general population.

\section{RESULTS}

Because the results are similar for men and women, results are presented only for men. Results for 30year-old men are presented because the differences between strategies are greater than those for older age groups.

\section{Base Case Analysis}

The base case analysis results use the best estimate probability values; more extreme estimates of probability values are used in sensitivity analyses.

RISK OF DEATH: Figure 1 and Table II show the numbers and timing of gallstone disease deaths that would occur over a lifetime for 100,000 30-year-old men managed by the three primary strategies. Gallstone disease deaths are those resulting from elective surgery for biliary pain, from urgent surgery for a biliary complication, and from the occurrence of gallbladder cancer. The number of deaths each year is calculated by multiplying the number of persons developing biliary pain, a biliary complication, or biliary cancer times the appropriate operative mortality rate (or by 1.0 in the case of gallbladder cancer). The total numbers of deaths for each strategy are shown by the areas under the curves. The cumulative death rate for Strategy A (immediate cholecystectomy) is $0.11 \%$ and for Strategy B (expectant management until pain recurs or until a complication occurs) is $0.14 \%$. Such 
Figure 2. Effect of five different natural histories in Strategy C: results of a sensitivity analysis for 100,000 30-year-old men. Percentages are yearly rates of a biliary complication. Numbers in parentheses are cumulative numbers of deaths occurring up to age 100 . Total deaths rise with rates up to $3 \%$ but then subsequently decline. Results for Strategy $A$ are shown in comparison.

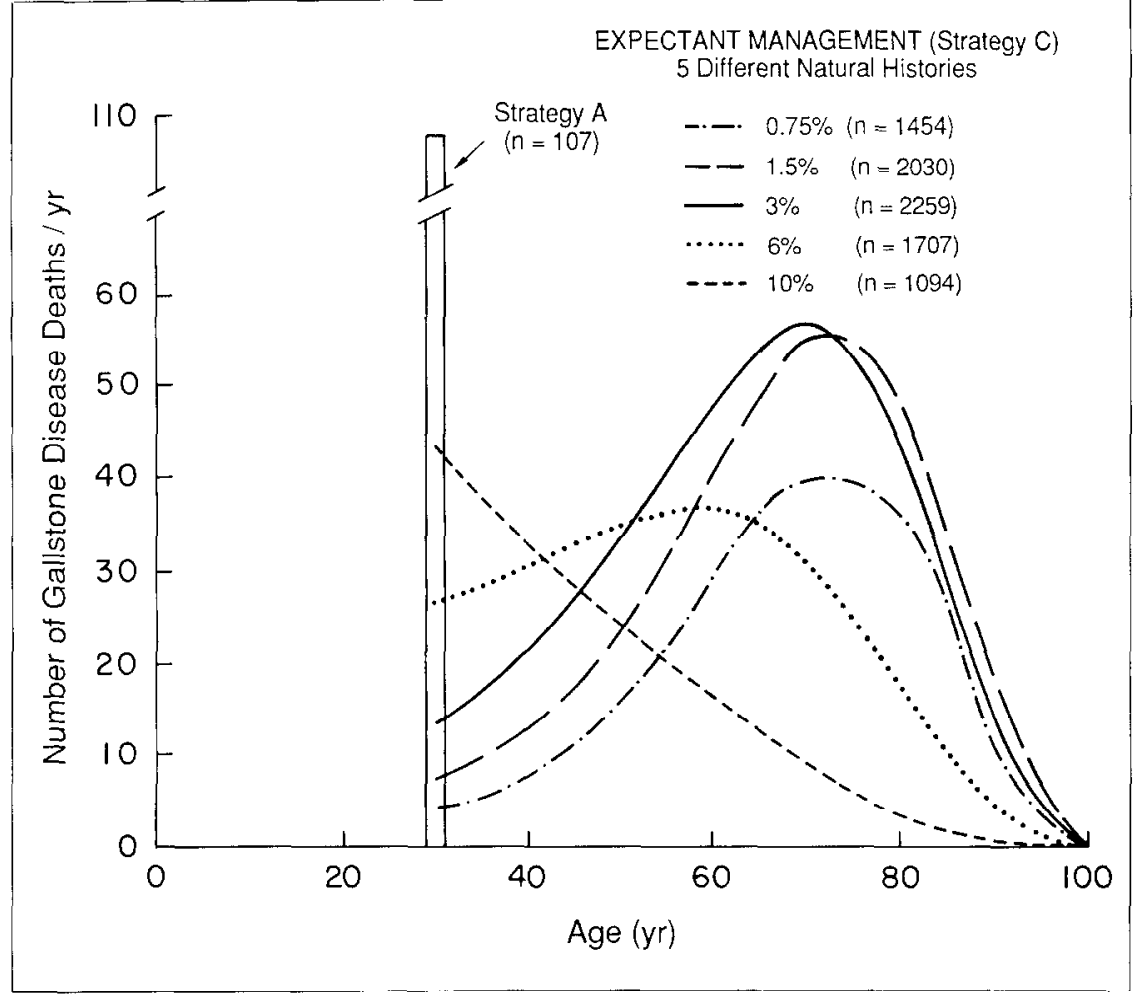

similarity of results occurs because the vast majority of persons using Strategy B have elective surgery within several years of the elective surgery that occurs in Strategy A. In contrast, for Strategy C (expectant management until a complication occurs) in the base case analysis ( $3 \%$ per year rate to develop a complication), the cumulative lifetime risk of gallstone-disease death is $2.3 \%$. Most of this mortality, however, occurs after age 65 ; the mortality risk by age 40 is only $0.19 \%$ and by age 50 is $0.46 \%$. These results are shown graphically in Figure 2. Thus, there are 2,259 deaths for 100,000 persons (i.e., a $2.3 \%$ lifetime cumulative death rate) managed by Strategy C. For persons whose gallstones are discovered at age 50 , the cumulative lifetime risk of death is about twice as high as for a 30 year-old, but because the deaths occur at older ages, the loss of life expectancy is only slightly increased.

Table II shows the contribution of gallbladder cancer to total deaths from gallstone disease. Gallbladder cancer may account for as much as $10 \%$ of gallstonedisease deaths for persons with symptomatic gallstones using Strategy C.

PROBABILITY OF CHOLECYSTECTOMY: For a 30-yearold man, the lifetime probability of having a cholecystectomy is $100 \%$ for Strategy A, nearly $100 \%$ for Strategy B, and $69 \%$ for Strategy C (base case analysis). For Strategy C, $31 \%$ of persons die from non-biliary causes without ever having a biliary complication or a cholecystectomy. All cholecystectomies are done electively for Strategy A, whereas 7\% of cholecystectomies for Strategy B and $100 \%$ for Strategy C are done urgently for complications. All persons in Strategy A have cholecystectomy at age 30, and 95\% in Strategy B have cholecystectomy by age 35 . For Strategy C, however, the probability of having a cholecystectomy by age 35 is only $14 \%$, by age 40 is $28 \%$, and by age 50 is $46 \%$.

Although the lifetime probability of cholecystectomy for a 30-year-old man choosing Strategy C is high, for persons discovered at older ages to have gallstones, the lifetime probability of cholecystectomy is substantially lower: $48 \%$ for a 50 -year-old man, and $27 \%$ for a 70-year-old man.

LIFE EXPECTANCY: Table III shows the average amount of life expectancy for each of the three strategies. Average life expectancy is similar for Strategy A (immediate cholecystectomy) and Strategy B (expectant management until pain recurs or until a complication occurs). Neither Strategy A nor B causes much loss of life expectancy-about two weeks-compared with the 40.51-year life expectancy of a 30-year-old man with no gallstone disease. Strategy $\mathrm{C}$ clearly results in some loss of life expectancy-up to about two months - compared with Strategy A. The results for 50-year-old men (not shown) are very similar. For 70 year-old men (not shown), the gains of Strategy A or B decrease to about two weeks compared with Strategy C.

\section{Sensitivity Analysis for Natural History}

There is some uncertainty about the natural history of persons with symptomatic gallstones. Figure 2 shows results for Strategy $\mathrm{C}$ for five different natural histories, i.e., rates that are higher and lower than the base case rate to develop a biliary complication. A recent study suggests that the yearly rate to develop a biliary complication in persons with "mildly symptomatic" gallstones may be about $1 \%$ per year over 20 years [24]. The results of using this rate can be consid- 


\section{TABLE III}

Life Expectancy Calculations

\begin{tabular}{|c|c|c|c|c|}
\hline \multirow[b]{3}{*}{ Strategy } & & \multicolumn{3}{|c|}{ Life Expectancy } \\
\hline & & \multirow[b]{2}{*}{$\begin{array}{c}\text { Average } \\
\text { Life } \\
\text { Expectancy } \\
\text { (years) }^{*}\end{array}$} & \multicolumn{2}{|c|}{ Life Expectancy Difference (days) } \\
\hline & & & $\begin{array}{l}\text { Compared } \\
\text { with } \\
\text { No } \\
\text { Gallstones }\end{array}$ & $\begin{array}{l}\text { Compared with } \\
\text { Immediate } \\
\text { Cholecystectomy } \\
\text { (Strategy A) }\end{array}$ \\
\hline \multicolumn{5}{|l|}{ Immediate cholecystectomy } \\
\hline \multirow{2}{*}{\multicolumn{2}{|c|}{$\begin{array}{l}\text { A-Cholecystectomy } \\
\text { Expectant management }\end{array}$}} & $40.48(40.47)^{\S}$ & $11(15)^{* *}$ & - \\
\hline & B-Until pain or complication & $40.48(40.47)$ & $14(17)$ & $2(2)$ \\
\hline \multirow[t]{3}{*}{ C-Until complication ${ }^{\dagger}$} & & & & \\
\hline & $0.0075 /$ year & $40.43(40.47)$ & $30(15)$ & $19(0)$ \\
\hline & $0.015 /$ year & $40.38(40.44)$ & $46(25)$ & $35(10)$ \\
\hline \multirow{2}{*}{ Rate of complication } & $\left\{\begin{array}{l}0.03 / \text { year } \mp \\
0.06\end{array}\right.$ & $\begin{array}{l}40.34(40.41) \\
40.32(40.37)\end{array}$ & $63(37)$ & $52(23)$ \\
\hline & $0.10 /$ year & $\begin{array}{l}40.32(40.31) \\
40.33(40.36)\end{array}$ & $65(56)$ & $\begin{array}{l}58(33) \\
54(41)\end{array}$ \\
\hline
\end{tabular}

* For comparison, a 30-year-old man with no gallstone disease has a life expectancy of 40.51 years.

t Rate of biliary pain: $0.41 /$ year; rate of biliary complication: $0.03 /$ year.

$¥$ Base case rate for Strategy $C$.

$\S$ Values in parentheses are calculations with $5 \%$ discounting.

** Indicates a loss of life of 11 days ( 15 with $5 \%$ discounting) of immediate cholecystectomy compared with no gallstone disease.

ered in Figure 2 and in Tables II and III by examining the incidence rates of $1.5 \%$ per year and $0.75 \%$ per year.

Since some autopsy studies have shown that gallbladder cancer may constitute up to $30 \%$ to $40 \%$ of gallstone-disease deaths $[20,21]$, we also performed a sensitivity analysis (not shown) in which gallbladder cancer rates were four times higher than the rates shown in Table I. Life expectancy was reduced by at most one to two weeks compared with the base case analysis.

\section{COMMENTS}

The two major reasons for choosing immediate treatment for symptomatic gallstones are to prevent recurrence of biliary pain and to prevent occurrence of biliary complications and death. Without any therapy, the probability of having biliary pain within one year is about $50 \%[6,15]$ and within two years is about $70 \%$ [6]. However, even when pain does recur, it tends to be very infrequent [6]. Furthermore, some evidence suggests that the incidence of pain may decrease with time [15]. Whether the recurrence rate of biliary pain is reason enough to warrant preventive treatment depends largely on personal value judgements of patients about the symptoms and inconvenience of biliary pain compared with the possible side effects and inconvenience of a treatment program.

If the main reason to choose therapy is not to prevent pain but rather to prevent gallstone disease death, is expectant management acceptable? The goal would be to delay therapy or to avoid therapy altogether. The acceptability of expectant management depends on the probability and age of death from a biliary complication or gallbladder cancer. It is of interest that the rationale for intervention - whether to prevent pain or to prevent death-is seldom discussed [1-3]. It would seem that different patients might value the two outcomes differently, suggesting that the outcomes should be considered separately.

The results of this analysis are expressed in two ways: as life expectancy (in Tables II and III) and as cumulative risk of death (in Figures 1 and 2). Individual patients and physicians may interpret these data in somewhat different ways. The principal finding of this analysis is that the mortality risk of a non-aggressive strategy, Strategy C (expectant management until a complication occurs), is of modest size in terms of life expectancy. In contrast, the cumulative risk of death of about $2 \%$ may be considered high by some patients, but it must be considered that the deaths that occur are, for the most part, at older ages.

Although immediate cholecystectomy does cause a gain in life expectancy compared with Strategy C, the gain is small. Perhaps surprisingly, there would be only a slight further gain from a nonsurgical therapy, such as lithotripsy or medical dissolution, that might someday be perfected so as to be completely, immediately, and permanently effective and to have no associated mortality. The life expectancy resulting from this ideal therapy would be the same as for a person who has no gallstones. The life expectancy of a person with no gallstones is, as shown in Table III, only slightly greater than for a person choosing prompt cholecystectomy.

One disadvantage of Strategy $\mathrm{C}$ is that expectant management may simply delay an operation that will ultimately be required and that will, at a later time, be associated with a higher mortality rate. The probability of needing an operation depends on the duration of risk (i.e., the age when gallstones are discovered) and on the yearly rate to develop a complication. Thus, a 30 -year-old man discovered to have symptomatic gallstones has a $69 \%$ chance of ultimately needing an operation, while a man whose symptomatic gallstones are discovered at age 50 has a $48 \%$ chance, and a man whose symptomatic gallstones are discovered at age 70 has a $27 \%$ chance. Lastly, if natural history is more benign than we have used (i.e., less than a $3 \%$ per year risk of complication), the chance of operation would further decrease.

An important perspective gained from this analysis is that the primary clinical feature that drives the decision about therapy is the mortality risk of expectant management. The safety of therapy appears to be a relatively minor issue because elective cholecystectomy, the current standard therapy, is already very safe; 
in comparison, nonsurgical therapy can improve survival time, as just shown, only slightly. The mortality risks from expectant management may be considered by some persons to be small, but they are not trivial. Thus, an effective, inexpensive, and permanent nonsurgical intervention would have an appeal to patients and physicians.

A practical clinical question is whether the mortality risk of expectant management will be considered by patients to be high enough to warrant an intervention. The magnitude is perhaps a $2 \%$ risk of death over a lifetime, but deaths occur mostly at older ages and cause a relatively modest loss of life expectancy. The decision about intervention to prevent this mortality will be determined in part by the risks and disadvantages of the intervention. The risks of elective surgery are generally known. Currently available nonsurgical therapies appear to be relatively safe for those patients who are candidates. One disadvantage of currently available nonsurgical therapies is that months of adjuvant chemical dissolution therapy may be required. More important is that gallstones may recur after dissolution in about $50 \%$ of persons after five years, and it is not yet known whether all such stones need to be detected and retreated. A requirement of follow-up monitoring and retreatment would be a disadvantage of nonsurgical therapy. Lastly, the costs for both medical dissolution therapy and lithotripsy are not insubstantial.

Whether the gains from nonsurgical therapy are worth the inconvenience and cost will be determined as a personal choice by patients. The magnitude of life expectancy gain for immediate treatment of symptomatic gallstones may be considered small in comparison with the gain of interventions in coronary disease, which may be measured in years [25]. Thus, until an inexpensive and very convenient nonsurgical therapy is available, we speculate that some patients may decide that the choice is a toss-up [26] and that expectant management is an acceptable choice.

There is some reason to believe that many patients may choose a compromise strategy of using expectant management for a trial period in order to assess their own biliary pain pattern $[10,15]$ (i.e., the frequency and timing of subsequent biliary pain). In such a strategy, therapy would be chosen if the pain episodes became frequent or severe enough. This strategy, which is between strategies B and C in terms of aggressiveness, will have a mortality that is higher than for $B$ but lower than for C. To model this strategy in an explicit way is not meaningful, we believe, because there is so much variability in patient choice. Nevertheless, we believe the current analysis can provide useful information for a patient who wishes to try such a strategy. For example, a 30-year-old man who tries the strategy for five years would risk about $0.1 \%$ chance of dying (i.e., the total number of deaths indicated in Figure 1 for Strategy C over five years), plus a $0.1 \%$ chance of operative death if an elective cholecystectomy were then done after five years.

It is important to consider that the results of the base case analysis for Strategy C are obtained under somewhat pessimistic assumptions about natural history that disfavor that strategy in our analysis. Thus, the complication rate that we have used-the $3 \%$ per year rate to develop a biliary complication-does not decrease over time. There is substantial uncertainty about the natural history of persons with symptomatic gallstones. Long-term follow-up is not available from the NCGS [6]. In another study about natural history [15], the incidence of biliary pain was approximately $50 \%$ in the first year, as in the NCGS; however, after 10 years of follow-up, $29 \%$ of persons had remained symptom-free. Recently published long-term data suggest a $1 \%$ per year rate to develop a complication [24].

The uncertainty about natural history deserves additional comment. This analysis is relatively insensitive to the yearly rate of biliary complications as long as the rate neither increases nor decreases substantially over time. Perhaps surprisingly we found that even an unusually high yearly complication rate- $10 \%$ compared with the base case yearly complication rate of $3 \%$ - actually decreases the case mortality rate, and it causes only slightly more life expectancy loss. The explanation for this counterintuitive finding is that there are two counterbalancing forces that affect life expectancy when the natural history is ominous. The increased yearly rate of complications causes an increased number of deaths in early years. However, because more cholecystectomies are done in early years, fewer persons are at risk to have biliary complications in later years, hence reducing the number of biliary deaths in later years. There are at least two theoretic scenarios in which natural history would have a great impact on the results and on the choice of management. If the course were benign initially and ominous in later years, immediate intervention would be strongly favored. Currently, there is no evidence to suggest that any subgroup of persons has such a natural history. Conversely, if the course were to become very benign in later years, expectant management would be favored.

This analysis is sensitive to the operative mortality rates after a biliary complication has occurred. If the operative mortality rates for an acute biliary complication were twice as high as those rates used in the base case analysis, then the life expectancy gain of immediate intervention would be approximately twice as great as shown in Table III. We believe, however, that such high operative mortality rates are unlikely to occur in most settings. The rates used in the base case were derived from sources that reflect the experience of a large number of institutions and are in quite close agreement with one another [11]. Persons with an especially high operative risk for mortality with a biliary complication, such as persons with cardiac disease, might consider prompt nonsurgical intervention with symptomatic stones.

We appreciate that mortality risk is the only one of the considerations in a patient's and physician's decision about therapy. Other important considerations include morbidity from biliary pain or complications, as well as the morbidity and inconvenience of therapy. We believe that many of these features are subtle and complex and cannot meaningfully be considered in a quantitative analysis such as this. We have focused on mortality and described mortality risk in terms of both life expectancy and lifetime mortality rates. Our goal has been to dissect out the importance of mortality risk, which we believe many patients and physicians will consider the single most important feature of the decision. The main message of this analysis is that mortality risk, at least in terms of life expectancy, need not dominate the decision about therapy. 
We have not provided a detailed consideration of cost for several reasons. We believe that the effect of uncertainty about natural history on the occurrence rates and timing of complications and death are most important to patients. Cost considerations are more important to society than to an individual patient, whose perspective we have taken here. Further, it is likely that the costs of currently available nonsurgical therapies, many of which are now experimental and in short supply, will decrease in the future because of technical improvements and competition. If that should happen, a major consideration in decisionmaking will be the magnitude of clinical benefit that can be derived from prompt intervention, which is what we have considered here.

We believe that these results may provide information that is useful for clinical practice. These results suggest that the mortality risk of expectant management in persons who have had biliary pain is relatively modest in terms of life expectancy. We believe that decisions about therapy may be elective and unhurried. And, although patient and physician preference in this matter remain to be assessed, we speculate that some patients and physicians will agree with the suggestion that symptomatic gallstones may be considered a "chronic disease" [4] that should receive intervention when a biliary complication occurs or when symptoms become sufficiently bothersome to the patient.

\section{REFERENCES}

1. Spiro HM: Clinical gastroenterology, 3rd ed. New York: Macmillan Publishing Co, $1983 ; 1080$.

2. Way $L W$, Sleisenger MH: Cholelithiasis and chronic cholecystitis. In: Sleisenger $\mathrm{MH}$, Fordtran JS. Gastrointestinal disease, 3rd ed. Philadelphia: WB Saunders, 1983; 1383-1389.

3. Malet PF: Chronic cholecystitis. In: Wyngaarden JB, Smith LH Jr, eds. Cecil textbook of medicine, 17th ed. Philadelphia: WB Saunders, 1985; 855-857.

4. Way LW: Surgical treatment and complications of gallstones. Practical Gastroenterology $1981 ; 5: 42-59$

5. McPhee MS, Greenberger NJ: Diseases of the gallbladder and bile ducts. In: Braunwald E, Isselbacher KJ, Petersdori RG, Wilson JD, Martin JB, Fauci AS, eds. Harrison's principles of internal medicine, 11th ed. New York: McGraw-Hill, 1987;

\section{8-1368.}

6. Thistle JL, Cleary PA, Lachin JM, Tyor MP, Hersh T, the Steering Committee, and the National Cooperative Gallstore Study Group: The natural history of cholelithiasis: the National Cooperative Gallstone Study. Ann Intern Med 1984; 101: 171175 .

7. Schoenfield LJ, Lachin JM, the Steering Committee, National Cooperative Gallstone Study: A controlled trial of the efficacy and safety of chenodeoxycholic acid for dissolution of gallstones. Ann Intern Med 1981; 95: 257-282.

8. Allen MJ, Borody TJ, Bugliosi TF, May GR, LaRusso NF, Thistle JL: Rapid dissolution of gallstones in humans using methyl tert-butyl ether. N Engl J Med 1985; 312 217-220.

9. Sackmann M, Delius $M$, Sauerbruch $T$, et al: Shock-wave lithotripsy of gallbladder stones: the first 175 patients. N Engl J Med 1988; 318: 393-397.

10. McSherry CK, Ferstenberg H, Calhoun WF, Lahmann E, Virshup M: The natural history of diagnosed gallstone disease in symptomatic and asymptomatic patients. Ann Surg 1985; 202: 59-63.

11. Ransohoff DF, Gracie WA, Wolfenson LB, Neuhauser D: Prophylactic cholecystectomy or expectant management for persons with silent gallstnnes: a decision analysis to assess survival. Ann intern Med 1983; 99: 199-204.

12. Ehnmark E: The gall stone disease: a clinical-statistical study. Acta Chir Scand 1939; 57 (suppl): 1-238.

13. Lund $\mathrm{J}$ : Surgical indications in cholelithiasis: prophylactic cholecystectomy elucidated on the basis of long-term follow-up on 526 non-operated cases. Ann Surg 1960; 151: 153-162.

14. Wenckert A, Robertson B: The natural course of gallstone disease: eleven-year review of 781 nonoperated cases. Gstroenterology 1966; 50: 376-381.

15. Newman HF, Northup JD, Rosenblum M, Abrams H: Complications of cholelithiasis. Am J Gastroenterol 1968: 50: 476-96.

16. Maringhini A, Moreau J, Melton LJ Iil, Hench VS, Zinsmeister AR, DiMagno EP: Gallstones, gallbladder cancer, and other gastrointestinal malignancies. Ann Intern Med 1987; 107: 30-35.

17. National Center for Health Statistics: Vital statistics of the United States, 1983-1985; unpublished data.

18. Bell ET: Pancreatitis: a study of 179 fatal cases. Surgery 1958; $43: 527537$. 19. U.S. Bureau of the Census: 1980 Census of Population (supplementary reports PC 80-S1-1). Washington, DC: Department of Commerce, 1981.

20. Conke L, Jones FA, Keech MK: Carcinoma of the gall-bladder: a statistical study. Lancet 1953; II: 585-587.

21. Amberg JR, Zboralske FF: Gallstones after 70: requiescat in pace. Geriatrics 1965; 20: 539-542.

22. Jarvinen HJ, Hastbacka J: Early cholecystectomy for acute cholecystitis. Ann Surg 1980; 191: 501-505.

23. Norby S, Herlin P, Holmin T, Sjodahl R, Tagesson C: Early or delayed cholecystectomy in acute cholecystitis? A clinical trial. Br J Surg 1983; 70: 163-165.

24. Friedman GD, Raviola CA. Fireman B: Prognosis of gallstones with mild or no symptoms: 25 years of follow-up in a health maintenance organization. $J$ Clin Epidemiol 1989; 42: 127-136.

25. Goldman L, Cook EF: The decline in ischemic hert disease mortality rates: an analysis of the comparative effects of medical interventions and changes in lifestyle. Ann Intern Med 1984; 101: 825-836.

26. Kassirer JP, Pauker SG: The toss-up. N Engl J Med 1981; 305: 1467-1469. 